\section{The correlation}

\section{between cell surface}

markers and clinical

features in choroidal

malignant melanomas

\section{Abstract}

Purpose Uveal melanoma continues to present problems when attempting to predict disease progression. This study attempts to identify markers indicative of the biological characteristics of cells isolated from samples of uveal melanoma, including adhesion (ICAM-1), immune reactivity (MHC Class I and II), cell cycle control (c-erbB-2, c-myc) and apoptosis control (bcl-2, p53) using dual parameter (DNA/MoAb) flow cytometry. Methods Sixty-three fresh tissue samples from choroidal melanomas were taken at enucleation. Samples were assayed for DNA content and cell cycle, the above antibodies together with positive (PHM-5) and negative $\left(2^{\circ}\right.$ FITC $\left.\mathrm{Ab}\right)$ controls. The clinical parameters sex, age, tumour location, cell type, tumour volume and presence of metastases were compared with the results and analysed with the non-parametric Mann-Whitney $U$-t-test. Results ICAM-1 expression proved to be the most clinically relevant, being present on a higher proportion of cells in tumours $>2000 \mathrm{~mm}^{3}$ (median 38, $n=19$ ) compared with the smaller tumours $<2000 \mathrm{~mm}^{3}$ (median 17, $n=26)(p=0.0015)$. Metastatic disease was present in 11 patients and did not correlate with any of the surface markers. C-myc, c-erbB-2 and MHC Class II expression were associated with cell type, all showing greater expression in spindle cell tumours than mixed/ epithelial types.

Conclusion These results show flow cytometry as a quick, easy method to provide a 'phenotypic profile' for these tumours, and identifies cell cycle control and adhesion molecule expression as important areas for further investigation. c-erbB-2 and $b c l-2$ positivity was typically seen on over $60 \%$ cells in each sample, indicating two potential targets for therapeutic intervention.

Key words Antibodies, Flow cytometry, Melanoma
J. LAWRY, Z. CURRIE, M.O. SMITH, I.G. RENNIE
Until recently, flow cytometry has been utilised only for the measurement of DNA ploidy and cell cycle measurements on cell suspensions generated from a range of solid tumours including uveal and cutaneous melanoma. We have previously reported on a simple, rapid process for the generation of dual-parameter (DNA/MoAb) stained cell suspensions that offers the potential to identify tumour and infiltrative cell populations, as well as to quantify antibody binding with cell cycle phases as well as DNA content (ploidy). ${ }^{1}$

The measurement of DNA ploidy and S-phase fraction has for some time been the only pathological application of flow cytometry. Several reports have appeared in the literature focusing on uveal melanoma. For example, Mooy et $a .^{2}$ measured DNA ploidy in nuclear suspensions generated from 132 samples of formalin-fixed, paraffin-embedded melanomas. Their results cite $37 \%$ aneuploidy, $63 \%$ diploidy, with a correlation $(p=0.009)$ between DNA ploidy and cell type. Irradiated melanomas were more aneuploid, and survival analysis showed DNA ploidy and the largest tumour diameter to be significant in predicting metastatic outcome $(p<0.03, p<0.001$; respectively).

In contrast, other reports based on the flow cytometric analysis of 32 choroidal melanomas ${ }^{3}$ found no correlation between histological type and ploidy, with an observation that greater proliferation was seen in mixed cell lesions than in spindle cell lesions.

Other indicators of proliferation may prove to be more useful. The oncoprotein c-myc plays a role in initiating cell cycle progression in both normal and metastatic cells. The measurement of this protein using the $6 \mathrm{E} 10$ mid-portion, 9E10 C-terminus antibodies, on a group of 24 ocular melanomas by immunohistochemistry has been reported to be a good indicator of proliferation, with a correlation between total myc staining and proliferative index. ${ }^{4}$
J. Lawry

M.O. Smith

Institute for Cancer Studies University Medical School Sheffield S10 2RX, UK

Z. Currie

I.G. Rennie

Department of

Ophthalmology

Royal Hallamshire Hospital

Sheffield S10 2JF, UK

Dr J. Lawry Institute for Cancer Studies University Medical School Beech Hill Road

Sheffield S10 2RX, UK

Tel: +44 (0)1142713774

Fax: +44 (0)1142713515

e-mail: j.lawry@sheffield.ac.uk

The flow cytometry facility is supported by the Yorkshire Cancer Research

Received: 24 February 1999 Accepted without revision: 25 March 1999 
It would also seem relevant to study the expression of other oncoproteins associated indirectly with proliferation (c-erbB-2), which is frequently associated with poorer prognosis in a range of solid tumours; and also with oncoproteins associated with the induction (p53) and inhibition ( $b c l-2)$ of the apoptotic process. bcl-2 inhibits most kinds of programmed cell death, providing selective survival advantage to various cell types. Whilst it has been seen to be normally expressed in ductal epithelia of the breast, overexpression was correlated with ER and PGR receptor expression in breast tumours, and was inversely correlated with Ki67 antibody binding (proliferation), and c-erbB-2, but not correlated with cerbB-1 (EGFr). $b c l-2$ expression was generally associated with favourable histopathological features, whilst loss of $b c l-2$ was linked to loss of hormonal regulation, increased de-differentiation and deregulated proliferation. ${ }^{5}$

However, it is not clear whether the findings reported for beast cancer are also true for uveal melanoma.

Melanoma evades the immune system in part by downregulating HLA Class I antigens on the cell surface, which are required for T-cell recognition. The oncogene c-myc may have a role in effecting this change in vitro, although the relationship between oncoprotein level and tumour antigenicity has not been established in human tumours. In a study of 94 skin melanoma lesions (46 primary, 46 regional metastases) using flow cytometry, Grover et al. ${ }^{6}$ measured Class I expression (using immunohistochemistry) and c-myc expression (using flow cytometry). c-myc expression was found on 91 tumours $(96 \%)$, with higher expression in metastatic compared with primary lesions. Class I expression was highly variable, with generally lower expression than primary tumours. Both parameters showed significant correlation between primary and metastatic disease, high oncoprotein being associated with down-regulation of cell surface antigens. In a further flow cytometric study ${ }^{7}$ uveal melanoma tumours and cell lines expressing MHC Class I were found to be insensitive to NK-cell-mediated lysis, in vivo and in vitro. Disruption of NK cell function increased the hepatic metastases.

Heymann et al..$^{8}$ reported that ICAM-1 cell-cell adhesion is essential for different immunological functions including non-MHC-restricted cytotoxicity. The shedding of soluble ICAM-1 is thought to impair immune recognition and lead to tumour escape. HILDA/ LIF or OSM increased ICAM-1 expression 2-fold but not sICAM-1. Tumour necrosis factor-alpha stimulated both forms. ICAM-1 upregulation was concomitant with an increase in non-MHC-restricted cytotoxicity of tumour cells mediated by LAK cells, and abolished by an antiICAM-1 antibody.

Clearly there is considerable value in measuring protein expression for a range of biological markers, if the data thus generated will enable a better understanding of the complex interaction of tumour proliferation and apoptotic pathways, and of host/ tumour immunology as well as tumour invasiveness. We now present the application of this technique to a group of 63 samples taken from 59 uveal melanoma tumours.
Multiple samples from the same patient occurred when melanotic and amelanotic lesions were clearly identifiable in the enucleated eye. Cells were isolated from these tumour samples, fixed and then stained with a panel of monoclonal antibodies selected to reflect four key mechanisms that cells within a tumour may need for disease progression: proteins involved in cell proliferation (c-myc, c-erbB-2), cell death mechanisms (p53, bcl-2), the host immune response (HLA-DR, W632) and tumour cell adhesion or migration (ICAM-1). Tissue samples were, however, variable in size, and hence cell yield. Not all samples were therefore applied to the whole antibody panel. Furthermore, the results presented for p53 represent only a pilot study on 18 samples.

\section{Materials and methods \\ Patient group}

Fresh tumour tissue was collected following enucleation, transported in liquid nitrogen to the laboratory, and then either stored, or dissociated to produce a single cell suspension. Patient details and clinical information were recorded in a database. Pathological analysis was undertaken by an ophthalmic pathologist.

\section{Tissue preparation}

Samples of primary ocular melanoma collected following enucleation were divided for storage, histological examination or immediate use. Single-cell suspensions were generated by dicing pieces of fresh tissue with scalpels in phosphate-buffered saline (PBS) containing antibiotics. Cells for flow cytometric analysis were washed in PBS, fixed in 1\% paraformaldehyde at room temperature for $5 \mathrm{~min}$ with frequent mixing, washed in PBS and permeabilised in $70 \%$ methanol cooled to $4{ }^{\circ} \mathrm{C}$, for a further $15 \mathrm{~min}$ period at room temperature, then stored at $4{ }^{\circ} \mathrm{C}$.

\section{Flow cytometric staining.}

Cell suspensions were washed in PBS then PBS containing $1 \%$ fetal calf serum (PBS/serum), $0.5 \times 10^{6}$ cells aliquoted into tubes, and the primary (test) antibody added at an appropriate concentration (typically 5 or $10 \mu l$ neat antibody). Staining was carried out for $30 \mathrm{~min}$ at $4{ }^{\circ} \mathrm{C}$, followed by washing in PBS/serum. The secondstage fluorescein isothiocyanate (FITC)-conjugated goatanti-mouse antibody (goat anti-mouse $\mathrm{F}\left(\mathrm{ab}^{\prime}\right) 2$, Caltag) was then added (100 $\mu \mathrm{l}$ at $1 / 100$ dilution in PBS/serum) for a further $30 \mathrm{~min}$ at $4{ }^{\circ} \mathrm{C}$ (protected from light). The samples were then washed in PBS/serum to remove excess antibody, and the pellet resuspended. The DNA fluorochrome, propidium iodide (PI, Sigma, Dorset, UK) was then added $(300 \mu \mathrm{l}$ at $50 \mu \mathrm{g} / \mathrm{ml}$ in PBS) for at least $30 \mathrm{~min}$ (protected from light), together with $50 \mu \mathrm{l}$ RNAse (5 U/ml, Sigma, Dorset, UK), after which samples were syringed (25 G needle) and filtered through a $50 \mu \mathrm{m}$ stainless steel mesh to remove any large aggregates of 
cells before analysis on the flow cytometer. The quality of DNA staining (peak CV) was improved by overnight storage at $4{ }^{\circ} \mathrm{C}$ in the final buffer containing PI DNA dye and RNAse.

\section{Monoclonal antibodies assessed}

The following panel of antibodies were used:

Negative control: FITC second-stage goat anti-mouse $f\left(a b^{\prime}\right) 2$ antibody (Caltag).

Positive control: PHM-5 epithelial/endothelial antibody (Silenus, Bio-Stat Diagnostics, Stockport, UK).

W632 MHC Class I antibody (a generous gift from the BTS Labs., Sheffield, UK).

HLA-DR MHC Class II antibody CR3/43 (DAKO, High Wycombe, UK).

ICAM-1 (CD54) adhesion molecule antibody (a generous gift from ICRF, London).

C-erbB-2 cytoplasmic domain antibody, code OM11952 (CRB, Cheshire, UK).

c-myc (against peptide mid-region) antibody 6E10 (CRB, Cheshire, UK).

bcl-2 antibody 124 (DAKO, High Wycombe, UK). p53 antibody DO-7 wild-type and mutant protein (DAKO, High Wycombe, UK).

\section{Flow cytometry}

Samples were routinely analysed on a FACSort benchtop flow cytometer (Becton Dickinson, Oxford, UK). Doublet discrimination was applied to exclude cell clumps using peak height and width analysis of the DNA fluorescence parameter. Ten thousand cells were routinely analysed for their DNA content, cell cycle and monoclonal antibody staining characteristics (\% positive cells and mean fluorescence industry). Antibody (FITC) fluorescence was recorded using a $530 \mathrm{~nm}$ band pass filter, and DNA dye fluorescence (PI) using a $620 \mathrm{~nm}$ long pass filter. Stored files were analysed for DNA ploidy and \% S-phase cells by the Modfit DNA software analysis package (Verity Software House, USA). Samples where the diploid $G_{0} / G_{1}$ peak had a coefficient of variation (cv) greater than 10 were excluded from the present study, and retested if possible. The study group cv range was 3.3-8.9, median 6.4.

\section{Data analysis}

Flow cytometric data was measured as median channels of fluorescence for DNA peak positions (linear fluorescence scales), and calculated mean fluorescent channels (log fluorescent scales) for antibody staining. Flow cytometric data were correlated with the clinical findings using a non-parametric Mann-Whitney $U$-t-test statistical package, and Spearman correlation coefficients calculated for percentage staining data generated by the antibody panel used (two-tailed significance).

\section{Results}

Tumour samples were taken from patients having enucleations for large choroidal melanomas. A total of 63 samples were taken from 59 tumours. Due to advances in more conservative treatments, the samples obtained by enucleation for this study were all large and therefore may be assumed to be at an advanced stage of disease progression. Two patient samples yielded two tumour samples, and one patient yielded three tumour samples, as areas with different clinical morphology (e.g. amelanotic vs pigmented) were identified.

This study used dual-parameter (DNA/MoAb) flow cytometry to look at membrane-associated antibody binding (ICAM-1, MHC Class I, MHC Class II), nuclear or cytoplasmic oncoprotein antibody binding (c-erbB-2, c$m y c, b c l-2$, p53) as well as DNA ploidy and cell cycle characteristics, and then compared these results with clinical parameters.

Sex, age of the patient, tumour location (ciliary body vs choroidal), cell type (spindle vs mixed or epitheloid), tumour volume $\left(<2000 \mathrm{~mm}^{3}\right.$ vs $\left.>200 \mathrm{~mm}^{3}\right)$ and the presence of metastatic spread were looked at and correlated with cell marker expression. Table 1 summarises the data from the present study and shows the median value of percentage positive cells stained with each antibody in the test panel, the sample size, and the statistical $p$ value for association with each of the clinical parameters measured. There were no correlations found between the proportion of cells staining for any of the marker panel used and patient age (mean age 62.4 years, range $23-97$ years) or tumour site (27 ciliary body, 32 choroidal), so these data are not shown.

A clear association exists between the size of the tumour (i.e. volume as measured by B-scan ultrasound) and the cellular expression of the adhesion molecule ICAM-1 (CD54). The median level of ICAM-1 expression for the whole patient group was $27 \%$ positive staining on tumour samples (range 0-92, $n=50$ ), with greater expression in the larger tumours $\left(>2000 \mathrm{~mm}^{3}\right.$, median 38 , range $3-77 ; n=19)$ compared with smaller tumours $\left(<2000 \mathrm{~mm}^{3}\right.$, median 17 , range $\left.0-92 ; n=26\right)(p=0.0015)$. There was also a weak association between ICAM expression and sex, ICAM-1 being expressed more in males (median 32, range 0-77; $n=24$ ) than females (median 18.5, range 0-92; $n=26)(p=0.049)$, which may suggest poorer prognosis between the sexes. ICAM-1 and tumour volume results are also illustrated graphically, using the division $<2000 \mathrm{~mm}^{3}$ versus $>2000 \mathrm{~mm}^{3}$, in Fig. 1. Fig. 1a shows the correlated data, whilst Fig. 1b uses 'box and whisker' analysis to indicate the range of ICAM-1 staining within each group. Whilst ICAM-1 expression may be indicative of an increased potential to metastasise, the findings of the present study showed no correlation with the clinical presence of metastases in the patient group. Metastases had been detected in 11 patients, but the maximum follow-up period was only 8 years and may therefore be too short. 


\begin{tabular}{|c|c|c|c|c|c|c|c|c|c|}
\hline & & Spindle & $\begin{array}{c}\text { Mixed/ } \\
\text { epitheloid }\end{array}$ & $<2000 \mathrm{~mm}^{3}$ & $>2000 \mathrm{~mm}^{3}$ & Diploid & Aneuploid & $\begin{array}{c}\text { No } \\
\text { metastases }\end{array}$ & $\begin{array}{c}\text { With } \\
\text { metastases }\end{array}$ \\
\hline ICAM-1 & $\begin{array}{c}n \\
m \\
p\end{array}$ & $\begin{array}{l}19 \\
20\end{array}$ & $\begin{array}{c}31 \\
27 \\
0.28\end{array}$ & $\begin{array}{l}26 \\
17\end{array}$ & $\begin{array}{l}19 \\
38 \\
\mathbf{0 . 0 0 1}\end{array}$ & $\begin{array}{l}33 \\
28\end{array}$ & $\begin{array}{l}17 \\
25 \\
0.65\end{array}$ & $\begin{array}{l}38 \\
23 \\
23\end{array}$ & $\begin{array}{l}12 \\
33 \\
0.15\end{array}$ \\
\hline$c-m y c$ & $\begin{array}{l}n \\
m \\
p\end{array}$ & $\begin{array}{l}69 \\
48\end{array}$ & $\begin{array}{l}52 \\
23 \\
\mathbf{0 . 0 1}\end{array}$ & $\begin{array}{l}14 \\
25\end{array}$ & $\begin{array}{l}12 \\
23 \\
0.63\end{array}$ & $\begin{array}{l}16 \\
21\end{array}$ & $\begin{array}{l}15 \\
24 \\
0.54\end{array}$ & $\begin{array}{l}23 \\
24\end{array}$ & $\begin{array}{c}8 \\
22 \\
0.93\end{array}$ \\
\hline c-erbB-2 & $\begin{array}{l}n \\
m \\
p\end{array}$ & $\begin{array}{l}19 \\
71\end{array}$ & $\begin{array}{l}27 \\
48 \\
\mathbf{0 . 0 2}\end{array}$ & $\begin{array}{l}29 \\
61\end{array}$ & $\begin{array}{l}14 \\
64 \\
0.81\end{array}$ & $\begin{array}{l}27 \\
66\end{array}$ & $\begin{array}{l}19 \\
48 \\
0.68\end{array}$ & $\begin{array}{l}36 \\
61\end{array}$ & $\begin{array}{l}10 \\
69 \\
0.38\end{array}$ \\
\hline Class I MHC & $\begin{array}{c}n \\
m \\
p\end{array}$ & $\begin{array}{l}12 \\
10\end{array}$ & $\begin{array}{l}19 \\
9 \\
0.82\end{array}$ & $\begin{array}{r}17 \\
5\end{array}$ & $\begin{array}{l}11 \\
11 \\
0.25\end{array}$ & $\begin{array}{r}20 \\
9\end{array}$ & $\begin{array}{l}11 \\
14 \\
0.84\end{array}$ & $\begin{array}{r}24 \\
9\end{array}$ & $\begin{array}{l}7 \\
9 \\
0.28\end{array}$ \\
\hline Class II MHC & $\begin{array}{c}n \\
m \\
p\end{array}$ & $\begin{array}{r}5 \\
39\end{array}$ & $\begin{array}{l}15 \\
10 \\
\mathbf{0 . 0 4}\end{array}$ & $\begin{array}{r}8 \\
10\end{array}$ & $\begin{array}{c}9 \\
17 \\
0.63\end{array}$ & $\begin{array}{l}11 \\
25\end{array}$ & $\begin{array}{l}9 \\
10 \\
0.25\end{array}$ & $\begin{array}{l}14 \\
15\end{array}$ & $\begin{array}{c}6 \\
16 \\
0.74\end{array}$ \\
\hline$b c l-2$ & $\begin{array}{c}n \\
m \\
p\end{array}$ & $\begin{array}{l}13 \\
66\end{array}$ & $\begin{array}{l}16 \\
62 \\
0.58\end{array}$ & $\begin{array}{l}10 \\
64\end{array}$ & $\begin{array}{l}14 \\
56 \\
0.64\end{array}$ & $\begin{array}{l}17 \\
63\end{array}$ & $\begin{array}{l}11 \\
65 \\
0.69\end{array}$ & $\begin{array}{l}19 \\
52\end{array}$ & $\begin{array}{l}10 \\
72 \\
0.14\end{array}$ \\
\hline p53 & $\begin{array}{l}n \\
m \\
p\end{array}$ & $\begin{array}{r}9 \\
42\end{array}$ & $\begin{array}{c}9 \\
17 \\
0.4\end{array}$ & $\begin{array}{r}7 \\
25\end{array}$ & $\begin{array}{c}8 \\
40 \\
0.18\end{array}$ & $\begin{array}{l}10 \\
32\end{array}$ & $\begin{array}{c}7 \\
29 \\
0.73\end{array}$ & $\begin{array}{l}14 \\
30\end{array}$ & $\begin{array}{l}4 \\
40 \\
0.75\end{array}$ \\
\hline$\%$ S-phase & $\begin{array}{c}n \\
m \\
p\end{array}$ & $\begin{array}{l}26 \\
14\end{array}$ & $\begin{array}{l}37 \\
10 \\
0.17\end{array}$ & $\begin{array}{l}36 \\
12\end{array}$ & $\begin{array}{c}22 \\
12 \\
0.52\end{array}$ & $\begin{array}{l}38 \\
11\end{array}$ & $\begin{array}{l}24 \\
14 \\
0.35\end{array}$ & $\begin{array}{l}50 \\
12\end{array}$ & $\begin{array}{l}13 \\
11 \\
0.27\end{array}$ \\
\hline
\end{tabular}

The calculated results for each antibody in the test panel are shown with each of the clinical parameters measured. Results shown include the sample size $(n)$, and the calculated median $(m)$ for the percentage of cells stained with each antibody in the group (background substracted), together with the correlated $p$ value for each antibody and each clinical parameter (spindle vs mixed/ epitheloid, $<2000 \mathrm{~mm}^{3}$ vs $>2000 \mathrm{~mm}^{3}$, diploid vs aneuploid, and the presence and absence of metastases). Significant $p$ values are shown in bold.

Oncoprotein antibody expression was significantly associated with cell type. c-erbB-2 was found in greater amounts in spindle cell tumours than in mixed/ epitheloid tumours (median 71\%, range 20-97, $n=19$ versus median $48 \%$, range $5-93, n=27)(p=0.023)$. The median percentage c-erbB-2 positivity for the whole group was $61 \%, n=46$. c-myc was also expressed more by spindle cell tumours: the total sample group gave a median $24 \%$ cells (range $3-93, n=13$ ), whilst spindle cell tumours showed a median of $47.5 \%$ cells stained (range $14-69, n=10)$ compared with mixed/epitheloid cell tumours with a median of $22.5 \%$ (range $8-52, n=21$ ) $(p=0.017)$. It is generally understood that spindle cell tumours have a better prognosis than mixed/epitheloid tumour, so these data would suggest that an increased potential to proliferate (increased c-myc expression, and increased putative growth factor expression (c-erbB-2)) is inversely associated with tumour aggression and

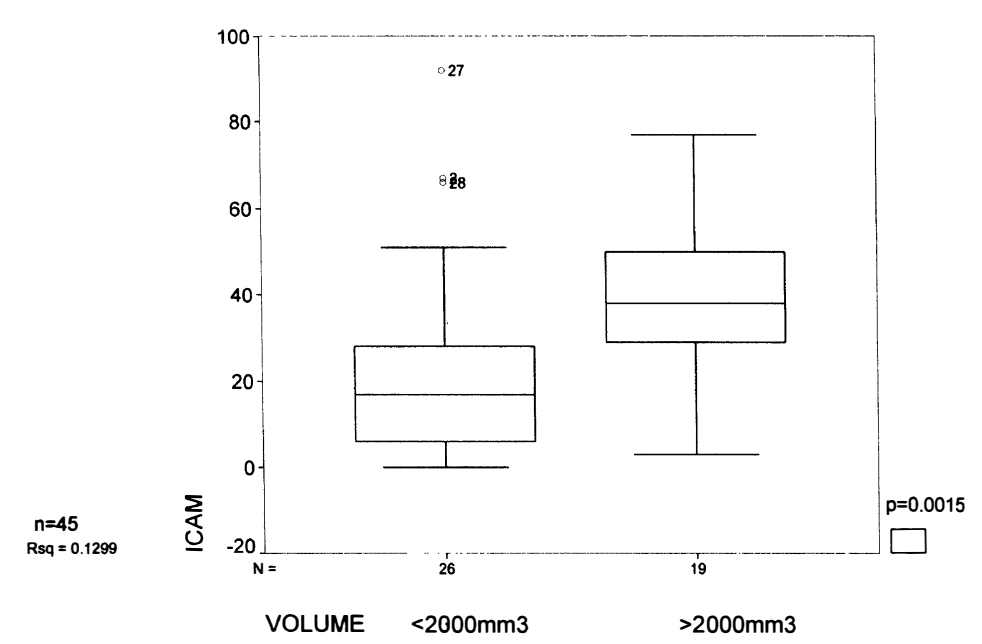

(b)

(a)

Fig. 1. (a) The correlation between tumour size and percentage ICAM-1 staining for the patient group. (b) Box and whisker analysis to indicate the range of antibody staining within each size group. 

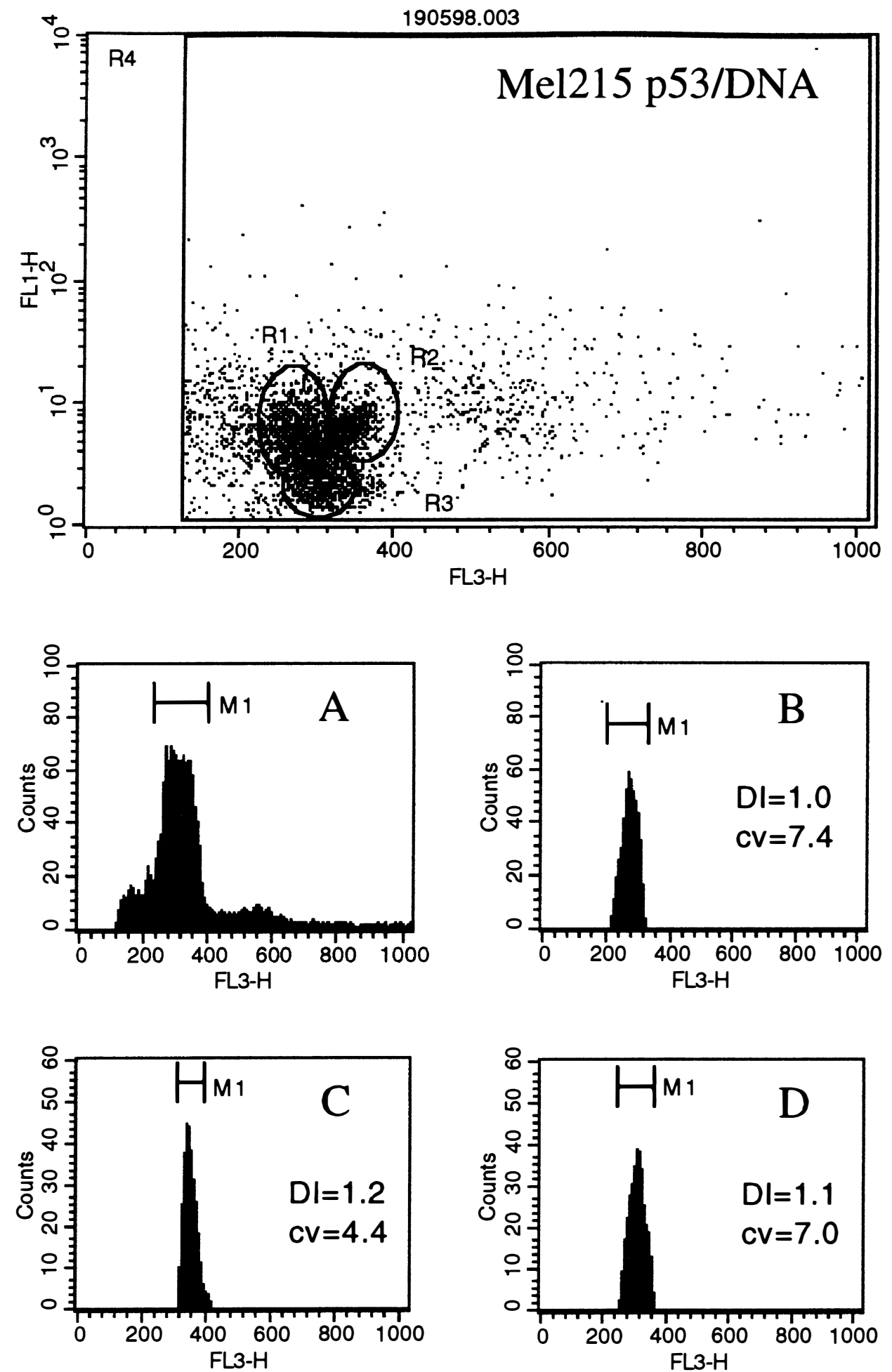

Fig. 2. A DNA multiploid uveal melanoma sample where selective gates ( $R 1, R 2, R 3)$ have been used based on p53 MoAb staining to isolate each ploidy population within an otherwise impossible histogram $(A)$. Populations positive for p53 are gated ( $R 1$ shown in $B ; R 2$ shown in $C$ ) with $p 53$ negative cells gated by R3, shown in (D). The calculated DNA Index (DI) and peak coefficient of varition (cv) are shown for each gated population.

metastatic ability. Once again, however, antibody

staining did not correlate with the presence or absence of metastatic disease.

The apoptotic markers used in the present study $(b c l-2$ and p53) failed to show any correlation with the clinical parameters analysed, with uniformly high levels of $b c l-2$ expression throughout the sample group (typically $60 \%$ positivity) and a lower level of positivity for $\mathrm{p} 53$ (typically 30\%). Fig. 2 illustrates a DNA multiploid uveal melanoma sample where selective gates have been used based on p53 MoAb staining to isolate each ploidy population. Dual-parameter antibody/DNA measurements are frequently able to assist with the identification of subpopulations of cells within the sample, which would not be possible with singleparameter staining. 
Whilst Class I expression was not found to show statistical significance between the groups analysed (pathology, tumour volume, DNA ploidy and the presence or absence of metastases), Class II expression was found to be statistically higher in spindle cell tumours compared with mixed/epitheloid cell tumours $(p=0.04)$. This may suggest that the improved prognosis associated with spindle cell tumours may be linked to MHC expression and the ability initiate an immune response against tumour cells, thereby preventing metastatic dissemination.

No statistical correlation was identified between DNA content (34 diploid, 24 aneuploid) and any of the clinicopathological parameters measured; nor with the calculated S-phase fraction. There was no statistical correlation between the S-phase fraction and the presence or absence of metastases, yet correlations did exist between \% S-phase cells and the percentage of cells labelling with c-erbB-2 and c-myc antibodies ( $p=0.003$ and 0.03 respectively). Table 2 summarises correlations identified between each flow cytometry parameter plus tumour volume, where 11 combinations show significance at $p=0.05$ or better.

\section{Discussion}

The results presented are taken from a significant number of patients bearing ocular melanoma and the data thus obtained therefore represent a valuable resource on what is still a rare, yet fatal disease. Our results also demonstrate the value of using the recognised technology of flow cytometry, where the disadvantages of loss of morphology are outweighed by the ability to measure rapidly and objectively over 10000 cells using two fluorescence parameters, and frequently identify discrete subpopulations of cells within a tumour sample. The protocol used is both simple and flexible, enabling the use of a wide range of monoclonal antibodies to suit the research interest. We have previously demonstrated that this protocol is suitable for most membrane-expressed antigens as well as cytoplasmic and nuclear markers. ${ }^{1}$

To date, flow cytometry has largely been used to measure DNA ploidy and cell proliferation (S-phase fraction). In contrast to previous studies we found no correlation between DNA ploidy and cell type. Mooy et $a l^{2}$, reported on a group of 132 archival samples of paraffin-embedded melanoma tissue $37 \%$ were aneuploid, $63 \%$ diploid) in which a clear correlation was found between DNA ploidy and cell type $(p=0.009)$. There are two possible reasons why the report by Mooy et al. and the present study do not agree: one is that we have only analysed 63 specimens (cf. 132); the second is that archival studies utilise thick tissue sections so represent a limited sample area, and may not contain detectable numbers of subpopulations of cells, visible in our study by the use of dual-parameter flow cytometry. However, the study presented here comprised 34 diploid (59\%) and 24 aneuploid tumours (41\%), and is therefore comparable to the study group of Mooy et al. ${ }^{2}$ (63\% diploid, 37\% aneuploid), which also showed DNA ploidy and the largest tumour diameter to be significant in predicting metastatic outcome $(p<0.03, p<0.01$,

Table 2. Spearman correlation coefficients for the antibody panel used (two-tailed significance)

\begin{tabular}{|c|c|c|c|c|c|c|c|c|}
\hline & c-erbB2 & $c-m y c$ & $b c l-2$ & $\begin{array}{l}\text { Class II } \\
\text { MHC }\end{array}$ & ICAM-1 & p53 & $\%$ S-phase & $\begin{array}{l}\text { Tumour } \\
\text { volume }\end{array}$ \\
\hline$c-m y c$ & $\begin{array}{l}n=27 \\
r=0.679 \\
p=0.000\end{array}$ & & & & & & & \\
\hline$b c l-2$ & $\begin{array}{l}n=21 \\
r=0.234 \\
p=0.3\end{array}$ & $\begin{array}{l}n=22 \\
r=0.005 \\
p=0.98\end{array}$ & & & & & & \\
\hline Class II MHC & $\begin{array}{l}n=16 \\
r=0.563 \\
p=0.023\end{array}$ & $\begin{array}{l}n=18 \\
r=0.508 \\
p=0.032\end{array}$ & $\begin{array}{l}n=13 \\
r=0.08 \\
p=0.788\end{array}$ & & & & & \\
\hline ICAM-1 & $\begin{array}{l}n=40 \\
r=0.193 \\
p=0.232\end{array}$ & $\begin{array}{l}n=30 \\
r=0.337 \\
p=0.68\end{array}$ & $\begin{array}{l}n=26 \\
r=0.072 \\
p=0.728\end{array}$ & $\begin{array}{l}n=20 \\
r=0.309 \\
p=0.184\end{array}$ & & & & \\
\hline p53 ${ }^{\mathrm{a}}$ & $\begin{array}{l}n=6 \\
r=0.771 \\
p=0.072\end{array}$ & $\begin{array}{l}n=7 \\
r=0.536 \\
p=0.215\end{array}$ & $\begin{array}{l}n=13 \\
r=0.622 \\
p=0.023\end{array}$ & $\begin{array}{l}n=5 \\
r=0.300 \\
p=0.624\end{array}$ & $\begin{array}{l}n=10 \\
r=0.778 \\
p=0.08\end{array}$ & & & \\
\hline$\%$ S-phase & $\begin{array}{l}n=46 \\
r=0.425 \\
p=0.003\end{array}$ & $\begin{array}{l}n=31 \\
r=0.389 \\
p=0.030\end{array}$ & $\begin{array}{l}n=29 \\
r=0.144 \\
p=0.456\end{array}$ & $\begin{array}{l}n=20 \\
r=0.051 \\
p=0.830\end{array}$ & $\begin{array}{l}n=50 \\
r=0.016 \\
p=0.908\end{array}$ & $\begin{array}{l}n=18 \\
r=0.219 \\
p=0.383\end{array}$ & & \\
\hline $\begin{array}{l}\text { Tumour } \\
\text { volume }\end{array}$ & $\begin{array}{l}n=43 \\
r=0.056 \\
p=0.585\end{array}$ & $\begin{array}{l}n=26 \\
r=0.130 \\
p=0.527\end{array}$ & $\begin{array}{l}n=24 \\
r=0.017 \\
p=0.937\end{array}$ & $\begin{array}{l}n=17 \\
r=0.234 \\
p=0.367\end{array}$ & $\begin{array}{l}n=45 \\
r=0.471 \\
p=0.001\end{array}$ & $\begin{array}{l}n=15 \\
r=0.018 \\
p=0.514\end{array}$ & $\begin{array}{l}n=58 \\
r=0.021 \\
p=0.874\end{array}$ & \\
\hline Class I MHC & $\begin{array}{l}n=27 \\
r=0.220 \\
p=0.270\end{array}$ & $\begin{array}{l}n=22 \\
r=0.316 \\
p=0.152\end{array}$ & $\begin{array}{l}n=14 \\
r=0.717 \\
p=0.004\end{array}$ & $\begin{array}{l}n=18 \\
r=0.417 \\
p=0.085\end{array}$ & $\begin{array}{l}n=31 \\
r=0.853 \\
p=0.000\end{array}$ & $\begin{array}{l}n=3 \\
r=1.0 \\
p=0.000\end{array}$ & $\begin{array}{l}n=31 \\
r=0.371 \\
p=0.843\end{array}$ & $\begin{array}{l}n=28 \\
r=0.181 \\
p=0.356\end{array}$ \\
\hline
\end{tabular}

Results shown include the sample group size $(n)$, median $(m)$ data value of the group (data being \% cells positive for the antibody after background subtraction from controls) and the significance value $(p)$. Significant results are shown in bold.

${ }^{a}$ The p53 data represent a pilot study and are based on only a low number of samples. 
respectively). We were unable to detect correlations with metastases, possible due to the fact that we can present only an 8 year follow-up.

When measuring DNA ploidy by flow cytometry, it is a simple task also to define the S-phase fraction as an index of proliferation. In the present study there was no correlation between the S-phase fraction and DNA ploidy; nor between S-phase, cell type or survival. Previous reports have similarly concluded that there are no significant correlations between the calculated S-phase fraction and prognosis. ${ }^{9-11}$

Whilst the S-phase fraction can be used as a direct means of quantifying cellular proliferation, there are other recognised ways of identifying whether a cell is undergoing cell cycle or not. For example, the Ki67 antibody recognising a histone epitope only exposed during DNA replication is frequently used. In one such study of 79 uveal melanomas ${ }^{12}$ S-phase correlated with Ki67 but not PCNA, the proliferating cell nuclear antigen. PCNA is one of the family of cell-cycle-specific proteins or cyclins, expressed at specific phases of the cell cycle and, under normal circumstances, rapidly degraded when the cell no longer requires them. Ki67 correlated with histopathological type and tumour size (Ki67 stained epitheloid cell type and large tumours) and also correlated with reduced survival. However, ploidy did not correlate with either the Ki67 or PCNA antigens.

Many oncoproteins have been identified as having either stimulatory of inhibitory roles in cell cycle progression. They may take the form of growth factor receptors such as the c-erbB-2 oncoprotein. This protein is one member of the epidermal growth factor receptor (EGFr) and transforming growth factor receptor (TGFr) family. These growth factors may exert either a stimulatory or an inhibitory effect on cell growth, respectively. In a study of 80 melanoma patients, van Dam et al. ${ }^{13}$ detected overexpression of IGFr-1 (11\%), EGFr (12\%), c-erbB-2 (24\%), c-ras (20\%) and c-myc (35\%), with levels of expression of IGFr, EGFr, c-erbB-2 and c-ras being higher in patients with recurrent disease. Diffuse c-erbB-2 positivity and p53 overexpression may both be associated with advanced dysplasia. ${ }^{14}$ Eccles et al. ${ }^{15}$ reported that c-erbB-1 (EGFr) and c-erbB-2 expression is closely linked to poor prognosis and an invasive/metastatic phenotype, and relative insensitivity to conventional therapies. Overexpression of c-erbB-2 is thought to be an early event in breast cancer; has been found to be more frequent in aneuploid tumours than diploid tumours; is correlated with increasing S-phase and ER negativity; and fluorescence intensity (level of expression) was correlated with prognosis. ${ }^{16}$ Our study also showed a correlation with S-phase $(p=0.003)$, and high levels of expression in the majority of the sample group, suggesting that c-erbB-2 may also be an early event in uveal melanoma.

Oncoproteins may have a role in cell cycle signalling. For example, the c-myc protein is implicated in both growth promotion and growth arrest depending upon the environment the cell is exposed to, and whether signals favour cell death or cell survival. Royds et al. ${ }^{4}$ investigated c-myc oncoprotein expression in 24 ocular melanoma samples using immunofluorescence, staining with the 6E10 mid-portion, and 9E10 C-terminus antibodies. Staining with c-myc antibodies was found to be indicative of proliferation, with correlations noted between total c-myc staining and the proliferative index. Our results also support this finding, with a correlation between \% S-phase cells and \% c-myc positivity $(p=0.003)$.

The p53 gene product functions as a tumour suppressor gene, being responsible for inducing either growth arrest or cell death through the process of apoptosis once DNA damage has been identified. The presence of wild-type p53 expression is therefore an indication of growth control, whilst mutant protein or a total lack of protein would indicate the lack of inhibitory growth control, and the possible survival of cells bearing DNA damage or mutations which would otherwise be killed by apoptosis. p53 was used only as a pilot study in the present report. However, preliminary results correlated p53 and bcl-2 expression $(p=0.023)$ and ICAM-1 expression $(p=0.008)$ but did not show any correlation between levels of p53 antibody binding and the clinical and pathological parameters used. It is also too soon to suggest whether this marker may be of value in determining a patient's response to therapy. Ryan et $a l .{ }^{17}$ assessed whether $c-m y c$ and $b c l-2$ were able to modulate p53 function by altering p53 subcellular trafficking during the cell cycle, and reported that coincident expression of $\mathrm{p} 53$ and $b c l-1$ in murine cell lines prolonged survival. Furthermore, co-expression of $b c l-2$ and c-myc was found to totally overcome p53-induced apoptosis and cell cycle arrest. This was thought to be by altering subcellular trafficking of p53 remaining in the cytoplasm at $\mathrm{G}_{1}$, instead of moving to the nucleus during this phase of the cell cycle. The $b c l-2$ gene product is a major protein in the apoptotic pathway serving to save cells from programmed cell death by inhibiting further signals in the pathway. The level of $b c l-2$ in the present study was high in almost all samples measured, and was found to correlate with p53 in the pilot study ( $p=0.023)$. However, p53 was not associated with particular cell types, tumour origin or tumour size. This suggests that bcl-2 expression may be an early event in uveal melanoma, and high expression of this protein may make it a candidate target for developing therapies.

Tumour survival must be considered to be a balance between the cellular response to survival or death signals, and the nature and extent of the host immune response. Tumour cell expression of major histocompatibility complexes (MHC) may be the most significant factor in deciding whether the host can mount a cytotoxic or natural killer response to the tumour. The protocol used in the present study enabled the use of antibodies against the MHC Class I and Class II determinants, and therefore the correlation of levels of staining with clinicopathological parameters. Our results showed MHC Class II to be a potentially significant factor, with reduced expression in the more aggressive mixed/epitheloid tumours and, theoretically, a reduced 
ability to activate an immune response. This was not noted with MHC Class I and is in agreement with a study of 41 melanomas in which an average of $85 \%$ cells stained with HLA A/B / C compared with only 7\% staining for HLA-DR. ${ }^{18}$ It is of interest to note that there may be a biological association between c-myc and MHC molecule expression. Grover et al. ${ }^{6}$ studied 94 skin melanoma samples (46 primary, 48 regional metastases), and found $96 \%$ to be c-myc positive, with higher expression in the metastatic samples. More importantly, c-myc expression correlated with down-regulation of both MHC Class I and Class II surface antigens - a result also found in the present study (Class II vs c-myc, $p=0.03$; Class I vs c-myc, $p=0.15$ ).

Cell-cell contact for many cell types is a prerequisite for survival, so the expression of intercellular adhesion molecules (ICAMs) may be considered to be an important property of tumour cells. However, our data indicate that the larger the tumour, and therefore the more likely it is to contain cells of metastatic phenotype, the greater is the expression of the ICAM-1 (CD54) protein. This would seem to support the view that, in this case, ICAM-1 expression may be a requirement for cell mobility or migration, and thus be a marker of the presence of metastatic cells in uveal melanoma.

In summary, we present data from a large group of uveal melanoma patients whose tumours have been dissociated, fixed and permeabilised, and stained with a monoclonal antibody and DNA fluorochrome. These multiparameter data have been correlated with a range of clinical and pathological criteria, and four have been identified as being of potential significance in the diagnosis, prognosis and management of this disease, namely: ICAM-1, MHC Class II, and the oncoproteins c$m y c$ and c-erb-b2. Our aim will be to follow these patients over a longer time period to assess which of the tested parameters may have a predictive value for the onset of metastatic disease.

The authors wish to acknowledge Dr M. A. Parsons for the pathological analysis of tissue specimens and Carmel Nichols for providing cell samples for flow cytometry.

\section{References}

1. Lawry J, Smith MO, Parsons MA, Rennie IG. Simultaneous cell cycle and phenotypic analysis of primary uveal melanoma by flow cytometry. Eye 1998;12:431-9.

2. Mooy C, Vissers K, Luyten G, Mulder A, Stijnen T, de Jong P, et al. DNA flow cytometry in uveal melanomas: the effect of pre-enucleation irradiation. Br J Ophthalmol 1995;79:174-7.

3. Fuchs M, Wohlrab W, Klapperstuck T, Fuchs U. DNA flow cytometry of malignant melanoma of the choroid. Ophthalmologe 1993;90:496-500.
4. Royds JA, Sharrard RM, Parsons MA, Lawry J, Rees RC, Cottam D, et al. c-myc oncogene expression in ocular melanomas. Graefes Arch Clin Exp Ophthalmol 1992;230:366-71.

5. Binder C, Marx D, Overhoff R, Binder L, Schauer A, Hiddermann W. Bcl-2 protein expression in breast cancer in relation to established prognostic factors and other clinicopathological variables. Ann Oncol 1995;6:1005-10.

6. Grover R, Ross DA, Richman PI, Robinson B, Wilson GD. c-myc oncogene expression in human melanoma and its relationship with tumour antigenicity. Eur J Surg Oncol 1996;22:342-6.

7. Ma D, Luyten GP, Luider TM, Niederkorn JY. Relationship between natural killer cell susceptibility and metastases of human uveal melanoma cells in a murine model. Invest Ophthalmol Vis Sci 1995;36:435-41.

8. Heymann D, Godard A, Raher S, Ringeard S, Lassort D, Blanchard F, et al. Human interleukin for DA cells/ leukaemia inhibitory factor and oncostatin $M$ enhances membrane expression of intercellular adhesion molecule-1 on melanoma cells but not the shedding of its soluble form. Cytokine 1995;7:111-7.

9. Richardson RP, Lawry J, Rees RC, Rennie IG. DNA index and \% S-phase fraction in posterior uveal melanoma: a 5 year prospective study of fresh tissue using flow cytometry. Eye 1997;11:629-34.

10. Elavathil LJ, LeRiche J, Rootman J, Gallagher RP, Phillips D. Prognostic value of DNA ploidy as assessed with flow cytometry in uveal melanoma. Can J Ophthalmol 1995;30:360-5.

11. Coleman K, Baak JP, Dorman A, Mullaney J, Curran B, Tiernan D, et al. DNA ploidy studies in choroidal melanoma. Am J Ophthalmol 1993;115:376-83.

12. Karlsson M, Boeryd B, Carstensen J, Franlund B, Gustafsson B, Kagedal B, et al. Correlation of Ki67 and PCNA to DNA ploidy, S-phase fraction and survival in uveal melanoma. Eur J Cancer 1996;32:357-62.

13. van Dam PA, Vergote IB, Lowe DG, Watson JV, van Damme $\mathrm{P}$, van der Auwere JC, et al. Expression of c-erbB-2, c-myc, c-ras oncoproteins, IGFr-1 and EGFr in ovarian carcinoma. J Clin Pathol 1994;47:914-20.

14. Wagner U, Sauter G, Moch H, NovotnaH, Epper R, Mihatsch MJ, et al. Patterns of p53, erbB-2, EGFr expression in premalignant lesions of the urinary bladder. Hum Pathol 1995;26:970-8.

15. Eccles SA, Modjtdhedi H, Box G, Court W, Sandle J, Dean CJ. Significance of the c-erbB family of receptor tyrosine kinases in metastatic cancer and their potential as targets for immunotherapy. Invasion Metastases 1994;14:337-47.

16. Stal O, Sullivan S, Sun XF, Wingren S, Nordenskjold B. Simultaneous analysis of C-erbB2 expression and DNA staining in breast cancer using flow cytometry. Cytometry 1994;16:160-8.

17. Ryan JJ, Prochownik E, Gottlieb CA, Apel IJ, Merino R, Nunez G, et al. c-myc, and bcl-2 modulate p53 function by altering p53 subcellular trafficking during the cell cycle. Proc Natl Acad Sci USA 1994;91:5878-82.

18. Meecham WJ, Char DH, Kaleta Michaels S. Infiltrating lymphocytes and antigen expression in uveal melanoma. Ophthalmic Res 1992;24:20-6. 